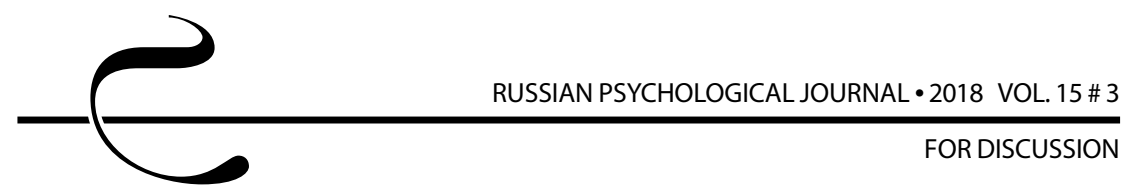

УДК 159.9.072

DOI: $\underline{10.21702 / r p j .2018 .3 .10}$

\title{
Психологический анализ медиатекста: образ животного в рекламном нарративе
}

\author{
Ирина М. Кыштымова \\ Иркутский государственный университет, г. Иркутск, Российская Федерация \\ E-mail: info@creativity.ru
}

\begin{abstract}
Аннотация
Ввеление. Проблема психологического анализа рекламного нарратива актуальна в связи с возрастающей ролью рекламной информации в развивающем коммуникативном пространстве. Новизна представленного исслеАования заключается в презентации метола психологического анализа медиапродуктов и обьяснения механизма использования образа животного Аля моделирования процессов трансляции рекламой экзистенциально значимых сообщений.
\end{abstract}

Метолы. Выявление транслируемых рекламой смыслов проводилось с помощью описанного в тексте метода имманентного анализа. Аля верификации сорормумированного на основе анализа сужАения о трансорормации образа животного в рекламном нарративе использовался семантический Аиффференциал, с помощью которого испытуемые последовательно оценивали образы животных: кошки, собаки, волка, медведя и енота, а также стимул «человек» и образ героя рекламного ролика - «енота». В исслеАовании принимали участие 103 человека: 77 старшеклассников и 26 стулентов.

Результаты. Выявлена Авойственность семантической структуры анализируемого ролика: он является транслятором не только прагматических, оправАанных коммерческой целью, но и экзистенциальных смыслов. Вторые, используясь как среАство привлечения внимания к рекАамируемому продукту, при этом обусловливают глубинное психологическое воздействие сообщения. Показано, что восприятие образа животного в рекламном нарративе опирается на его антропоморфные характеристики, трансорормирующиеся в художественном пространстве ролика. Определен негативный характер изменения семантики образа животного поА влиянием его рекламной презентации.

ОбсужАение результатов. Сравнение семантики «енота» с семантикой «человека» и налеленных стереотипным значением животных позволило выявить его семантический статус и предположить, что антропоморфная «обыкновенносты этого животного актуализирует процессы зрительской идентификкации и трансляции значимых Аля фрормирования мотивации экзистенциальных смыслов. Сравнение семантики внеконтекстного стимула «енот» с семантикой героя рек^амного ро^ика позволи^о определить характер семантической трансформации образа 
для дискуссии

животного в рекламном нарративе и верифрицировать полученное в процессе имманентного анализа сужление о провокации анализируемым рекламным роликом мотивации суициАального повеАения.

\section{КАючевые слова}

психологический анализ, имманентный анализ, психосемиотический поАХОА, нарратив, рек^ама, образ животного, семантика, архитектоника, прагматический смысл, экзистенциальные смыслы

\section{Основные положения}

- имманентный психологический анализ позволяет определить транслируемые медийным нарративом, структурированным по типу художественного, смыслы;

- имманентный анализ предполагает последовательное изучение образной системы, архитектоники, выразительных средств моделирования нарратива;

- рекламный нарратив может характеризоваться Авойственной смысловой структурой: прагматической и экзистенциальной; второй структурный уровень, используясь как среАство привлечения внимания к рекламируемому продукту, оказывается при этом психологически Аоминантным;

- характер семантической трансфрормации образа животного в рекламном нарративе определяется его исходной (внеконтекстной) антропоморфннй семантикой и художественными особенностями рекламного ролика.

\section{Для цитирования}

Кыштымова И.М. Психологический анализ медиатекста: образ животного в рекламном нарративе // Российский психологический журнал. 2018. T. 15, № 3. С. 209-228. DOI: 10.21702/rpj.2018.3.10

\section{Psychological Analysis of Media Text: The Animal Image in Advertising Narratives}

\section{Irina M. Kyshtymova}

Irkutsk State University, Irkutsk, Russian Federation

E-mail: info@creativity.ru 


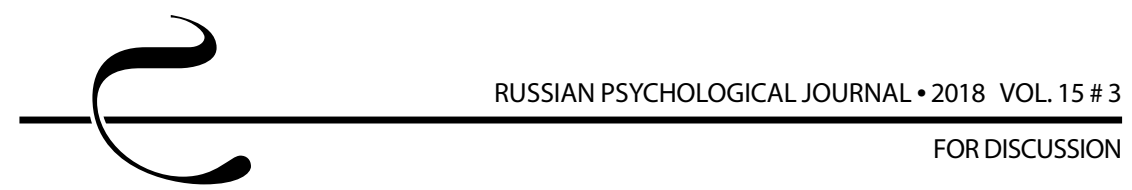

Abstract

Introduction. The increasing role of advertising in the communicative space determines the urgency of undertaking psychological research on advertising narratives. This study, for the first time, presents the method for psychological analysis of media products and explains the mechanisms of using images of animals for modeling the processes advertising uses to transmit existential messages.

Methods. The meanings transmitted by advertising were revealed using the method of immanent analysis. The study employed the semantic differential technique to verify judgements on the transformation of animal images in advertising narratives. Using semantic differential scales the respondents assessed images of animals such as: a cat, a dog, a wolf, a bear, and a raccoon; and also of a 'human' image, as well as a 'raccoon' as the main character of the advertising video. The study sample was comprised of 77 high-school and 26 university students (total $N=103$ ).

Results. The study established the duality of the semantic structure of the analyzed video. It transmits not only pragmatic meanings (justified by its commercial purposes), but also existential ones. Existential meanings are used as a means of attracting consumers' attention to the advertised product, while determining a deep psychological impact of the message. In advertising narratives an individual's perception of the animal image rests upon its anthropomorphic characteristics transformed in the artistic space of a promotional video. The study revealed negative changes in the semantics of the animal image under the influence of its presentation in advertising.

Discussion. Comparing the 'raccoon' semantics with the semantics of a 'human' and the animals with stereotyped meanings revealed its semantic status and led to the assumption that the anthropomorphic 'ordinariness' of this animal actualizes consumers' processes of identification and transmission of existential meanings important to forming their motivation. Comparing the semantics of the non-contextual 'raccoon' stimulus with the semantics of a 'raccoon' as the main character of the advertising video allowed authors to determine semantic transformations of the animal image in advertising narratives. The study also considered an issue of potentially provoking suicidal behaviour by watching the analyzed advertising video.

\section{Keywords}

psychological analysis, immanent analysis, psychosemiotic approach, narrative, advertising, animal image, semantics, architectonics, pragmatic meaning, existential meaning

\section{Highlights}

- Immanent psychological analysis is capable of identifying the meanings transmitted by media narratives which are structured as artistic ones.

- Immanent analysis involves a sequential study of a metaphorical system, architectonics, and expressive means for narrative modeling. 
Advertising narratives may have a dual semantic structure (pragmatic and existential). The latter is psychologically dominant as it is used as a means for attracting attention to the advertised product.

- The semantic transformation of the animal image in the advertising narrative is determined by its original (non-contextual) anthropomorphic semantics and artistic features of a promotional video.

\section{For citation}

Kyshtymova I. M. Psychological Analysis of Media Text: The Animal Image in Advertising Narratives. Rossiiskii psikhologicheskii zhurnal - Russian Psychological Journal, 2018, V. 15, no. 3, pp. 209-228 (in Russian). DOI: 10.21702/rpj.2018.3.10

Original manuscript received 22.11.2017

\section{Введение}

Активное преобразование коммуникативного пространства, проявляющееся как в его структурных, так и качественных трансформациях, ставит перед психологами важную задачу понимания механизмов влияния изменяющейся информационной среды на развитие человека. Насыщенность медийного контента рекламными сообщениями, их императивность, смысловая и эмоциональная концентрированность обусловливают как привлекательность рекламы, так и опасность провокации деструктивных форм поведения, прежде всего, у детей и молодежи. С другой стороны, важно определять развивающий потенциал медийных текстов, возможность их использования в обучающих и воспитательных процессах. При этом задача создания методов для определения особенностей влияния на психику медианарративов, в том числе рекламных, не решена. Остается актуальной проблема понимания механизмов, определяющих характер восприятия рекламного сюжета и формирующих у потребителя готовность к определенному типу поведения. Построение рекламных сообщений по типу художественных, активное использование образных средств при их моделировании позволяют транслировать помимо прагматических сообщений, направленных на актуализацию потребительской мотивации, также иные значимые смыслы, оказывающие влияние на установки, ценности и поведение потребителей рекламы. Их определение представляется важной психологической задачей, решение которой требует интеграции методов анализа, разработанных в рамках разных научных подходов, позволяющих учитывать сложную полисемиотическую природу рекламы, использующей при моделировании сообщений разные типы знаков.

Рекламный ролик представляет собой нарратив, особенностями которого являются смысловая концентрированность и активное использование 


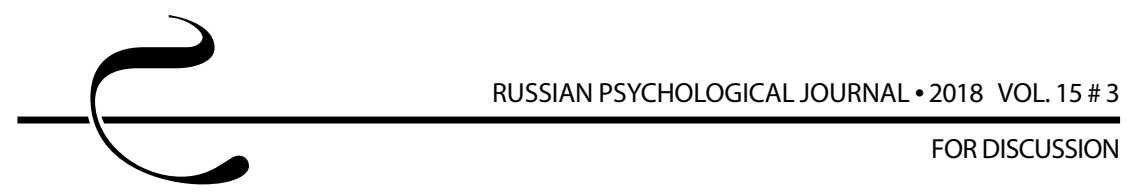

художественных приемов, обеспечивающих эмоциональность рекламного сообщения, его суггестивный эффект. Реклама, являясь продуктом коммерческого предприятия и решая задачу продвижения рекламируемого продукта, в то же время, как художественный текст, может оказывать глубокое влияние на эмоции, сознание и установки человека. Подходы к анализу художественных нарративов, разработанные применительно к литературным текстам, используются сегодня в рамках нарратологии, в психологии и междисциплинарных медиаисследованиях $[1,2,3,4]$. Нарратологический подход интегрирует продуктивные приемы анализа для исследования разных типов нарративов, в том числе - кинонарративов, к которым можно отнести рекламный ролик.

При этом концентрированность на последовательности воспроизводимых в тексте событий ограничивает возможности нарративного подхода в решении задачи целостного анализа сложного художественного текста, в связи с чем представляется продуктивным обращение к формальному подходу в литературоведении (Р. Якобсон, М. Бахтин, М.Л. Гаспаров). Важность положений формальной школы для разработки алгоритма психологического анализа сложного полизнакового художественного текста подчеркивал Л.С. Выготский: «настоящая психологическая теория сумеет объединить те общие элементы, которые, несомненно, существуют у поэзии и музыки... и этими элементами окажутся элементы художественной формы» [5, с. 101]. Доминантная роль формальных характеристик медиатекста в порождении его смысла легитимизирована семиотической теорией медиа $[6,7]$ и используется в анализе рекламы [8], при этом в ряде работ подчеркивается недостаток семиотического подхода, связанный с изолированностью анализируемых символических маркеров текстуальности: языка и образов - от социального контекста, что в полной мере компенсируется в техниках дискурсивного анализа $[9,10]$, акцентирующего внимание на социально обусловленном языковом опыте. Среди специфичных для медиапсихологических исследований методов наряду с лабораторным экспериментом, телеметрией, наблюдением и опросами обозначают только один, используемый при психологической интерпретации текста - контент-анализ [11, с. 31], но его сконцентрированные на лексике возможности ограничены для понимания актуализируемых медиатекстом психических трансформаций. Сходная особенность - концентрация аналитических усилий на исключительно содержательных характеристиках текстов - характерна для методов определения психической безопасности рекламы [12] и детского контента [13]. Необходимость разработки способов определения трансформационной функции медиатекстов, которая должна стать объектом исследования медиапсихологии [14], определила задачу нашего исследования. 
Для выявления психологических эффектов медиатекста важна концентрация исследователя на его формальных признаках, обусловливающих «чувственное вовлечение», когда человек «переживает гораздо больше, чем понимает» при том, что «именно переживание влияет на поведение» [15, с. 365]. Поэтому в качестве базового основания представляемого метода анализа медийного текста использован психосемиотический подход, позволяющий в полной мере реализовать принцип системности, исследуя формальные и содержательные компоненты медиатекста в их взаимосвязи, обусловливающей прагматику текста - особенности его восприятия потребителем [16]. Необходимость такого подхода подчеркивал Б. В. Ломов: «важность, многообразие и сложность психологических проблем знаков и знаковых систем дают основание думать о становлении и развитии целой научной отрасли... называемой нами психосемиотикой» $[17$, с. 283]. Психосемиотическое исследование медиатекста предполагает анализ его семантики, синтактики (формальных характеристик текста, знакового дизайна) и, на их основании, - прагматики («отношения знаков к конкретной деятельности и общению» [17, с. 264], к процессам психических трансформаций адресата знакового послания).

\section{Методы}

\section{Имманентный анализ рекламного нарратива}

Для выявления психологически значимых смыслов медийного, в том числе рекламного, нарратива мы предлагаем использовать метод имманентного анализа [18], который применительно к анализу литературных произведений определен как анализ, «не выходящий за пределы того, о чем сказано в тексте» $[19$, с. 8], что позволяет минимизировать субъективность интерпретатора. Отношение к предмету нашего анализа - медийному нарративу как семиотическому объекту - предполагает выявление его содержательных и синтаксических (формальных) особенностей, обусловливающих трансляцию психологически значимых смыслов. Обосновываемый метод интегрирует элементы психосемиотического, нарративного и «формального» подходов.

Имманентный анализ медиатекста трехчастен - он предполагает последовательное изучение: 1) особенностей его образной системы (иконический уровень); 2) последовательности действий или взаимосвязанных мотивов (уровень архитектоники); 3) звукового сопровождения (аудиальный уровень). На каждом уровне анализа последовательно решается несколько задач, постановка которых связана с особенностями анализируемого текста.

Презентация разрабатываемого метода комплексного психологического анализа медиатекста проведена на примере анализа рекламного ролика клея «Секунда» [20], выбор которого обусловлен двойственностью его восприятия: с одной стороны, ролик получил высокую оценку в профессиональном 


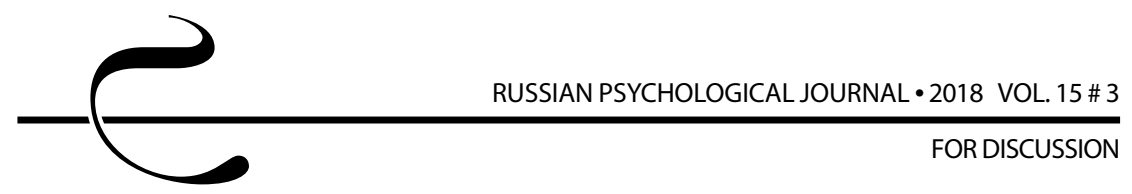

сообществе специалистов в области рекламы как эффективный и креативный рекламный продукт (ролик стал победителем на церемонии AdAwards); с другой, особенности ролика позволяют предположить, что он психологически деструктивен.

Проблема психологической деструкции медиапродукции является горячо обсуждаемой в научном сообществе [21, 22, 23, 24, 25, 26]. При этом суждения о возможности медиатекстов провоцировать деструктивные формы поведения противоречивы: например, в зарубежных источниках признается влияние на суицидальное поведение рассказанных в медиаисточниках реальных историях самоубийств, но признается, что данные о влиянии медиатекстов, структурированных по модели художественных, неоднозначны: одни из них «не оказывают никакого влияния, другие же повышают частоту суицидального поведения» [27, с. 102].

Действительно, определение психологического эффекта художественного текста - сложнейшая задача: психологический эффект медианарратива, обладающего свойствами художественности, обусловлен прежде всего его синтаксическими (формальными) свойствами; анализ такого медиапродукта затруднен необходимостью апелляции к теории художественной формы и положениям, разработанным в рамках разных дисциплин и научных парадигм. Ограничение исследователя анализом лишь содержания текста при выявлении его психологического потенциала не позволяет решить задачу психологической экспертизы: например, сами по себе «красивое», «героическое», «безобразное» или «ужасное» - эстетические категории, не определяющие психологический эффект художественных текстов, в которых они реализованы, особенности воздействия этих текстов будут зависеть от их формальных характеристик: так, не все фильмы ужасов психологически деструктивны, а фильмы о героях созидательны. Это и обусловливает важность создания методов комплексного психологического анализа медиатекстов, позволяющих выявлять их развивающий или нарушающий психологическую безопасность потенциал.

На первом этапе представляемого исследования анализу подверглась образная система анализируемого рекламного текста. Герой ролика - «енот». Выбор животного в качестве действующего персонажа художественных нарративов оправдан универсальностью его восприятия и, согласно суждению Л.С. Выготского, дает возможность автору «изолировать и сконцентрировать один какой-нибудь аффективный момент в таком условном герое» [5, с. 122]. При этом «енот» не относится к числу животных с жестко стереотипной семантикой, он не наделен символическим значением и закрепленной в культуре ролью. Можно предположить, что это обстоятельство, во-первых, будет способствовать активизации процесса идентификации зрителя с героем при 
восприятии текста; во-вторых, явится основанием доминантного контекстуального (заданного художественными обстоятельствами) обусловливания семантики героя.

Другой важной особенностью образа героя ролика является его абсолютная статичность - «енот» предстает в виде незамысловатой фаянсовой статуэтки, простота которой подчеркнута непритязательностью безыскусственной формы, бежево-молочным цветом блеклой фигуры с покорно сложенными лапками. Черная полоса опоясывает часть головы животного с едва намеченной областью глаз. Унылый безжизненный серый фон подчеркивает депрессивность образа. При этом «енот»- единственный герой, «лицо» в анализируемом ролике, фокальный персонаж, чей «взгляд на мир» актуализирован в рекламном нарративе, в полной мере реализующем прием фокализации - «отображения художественной реальности с определенной точки зрения» [1, с. 88].

Образная система рекламного ролика включает также центральные для отдельных эпизодов предметы, служащие одновременно фоном и мотивационными символами: мост, вокзальный перрон, поезд, ступени подземного перехода, осколки, дорога, машина, механический пресс, пистолет, мышеловка, взрывное устройство, блендер, фальшфейер (свеча бедствия), комната. Все образы символически нагружены, причем напряженность их символической семантики последовательно возрастает. Значение движения, изменения, перехода, заданное образами моста, железной и автомобильной дорог, подземного перехода, трансформируется в ролике в семантику перехода в мир иной - семантику смерти посредством образов: пистолета, взрывного устройства и фальшфейера, а также образов разрушенного тела «енота» - осколков фигурки, появляющихся в ролике трижды. Символическая повторяемость образа разбитого, раздавленного «енота» маркирует тему разрушения, подчеркивает безальтернативность смерти в разных жизненных обстоятельствах, навязывает ее.

На образном уровне ролика противопоставлены «енот»- маленький, слабый, пассивный, и мир - жесткий, грубый, холодный, безразличный. Жизненный мир символически обозначен образами бетонных свай моста, грязной дороги и металлического блеска рельсов, надвигающегося поезда и давящего колеса машины, холодных каменных ступеней, безжалостного пресса и неопрятной бедной комнаты. Условности образа героя, представленного фаянсовой статуэткой, противостоит реальность окружающего мира - презентующие его образы являются «настоящими»; натурализм, узнаваемость окружающей среды усиливают погружение зрителя в художественное пространство рекламного текста, объективированное восприятием фокального персонажа. 


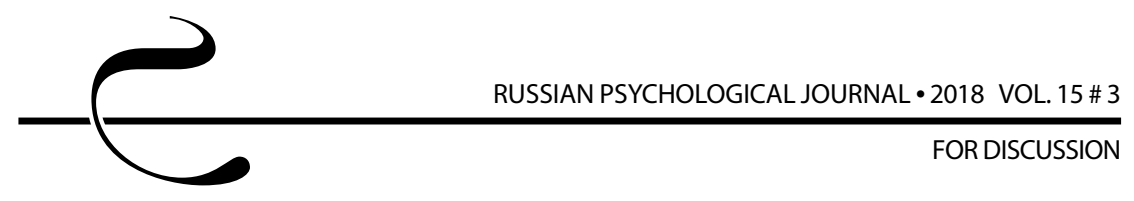

На следующем этапе анализа выявлялись особенности его архитектоники. Анализируемый ролик длится 1 минуту, за это время в ускоряющемся темпе сменяются девять эпизодов, в восьми из которых «енот» погибает или должен погибнуть. Сцены первого эпизода спаяны мотивом безысходности: одинокая фигура «енота» на мосту - акцентированные черным ее глаза - жесткая бетонная стена - падение вниз (полет) и - мгновенный переход ко второму эпизоду: фигура енота на перроне. Эпизод моделируется как визуально незавершенное действие, при этом не вариативное, и незавершенность усиливает, актуализирует мотив смерти.

В трех эпизодах мотив гибели реализован до конца: «енот» разбивается о грязные каменные ступени подземного перехода, его переезжает колесо грязной машины, он превращается в осколки под ударами механического пресса. Мотив смерти связан с мотивом невыносимости жизни - действие провоцируется окружающей обстановкой, визуально представленной серостью, холодом, грязью, безжизненностью пространства.

Депрессивный фон быстро сменяющихся эпизодов, представляющих собой разные формы ухода «енота» из жизни, поддерживается незамысловатым музыкальным фоном. Его минорный лад (тональность ля минор), медленный темп создают общее настроение глубокой печали. Первый раздел начинается тихим звучанием в высоком регистре в партии сопровождения интонации нисходящей малой терции (движение через один звук), подобно горестным вздохам. На ее однообразном фоне в верхнем голосе вступает мелодическая фраза с нисходящими плачущими секундовыми интонациями (постепенное движение вниз), передающими состояние одиночества и страдания. Далее динамика усиливается, примитивные мелодические ходы по звукам аккордов становятся громче на фоне фигураций по простейшим аккордам с нисходящим движением баса, усиливая внутреннее напряжение. В третьем кульминационном разделе мелодической фразы уже нет, остается только примитивное сопровождение из второго раздела, звучащее громко в высоком регистре с теми же навязчивыми басами. Музыка усиливает транслируемое визуальными средствами ощущение безысходности; если она и «не диктует непосредственно тех поступков, которые должны за ней последовать, то все же от ее основного действия... зависит то, какие силы она придает жизни и что оттеняет вглубь» [5, с. 313]. В анализируемом ролике музыка поддерживает мотив бессилия и смерти.

Противостояние «енота» и мира в каждом из восьми эпизодов заканчивается поражением героя, его смертью. В девятом, кульминационном, по замыслу авторов, эпизоде к фарфоровой фигурке «енота» тянется рука человека, кладущего на стол яркий тюбик клея. Рациональный замысел - реализовать экзистенциально значимый мотив «восстания из пепла», и посредством 
его актуализировать потребительскую мотивацию, связав рекламируемый продукт с позитивными эмоциями, можно назвать креативным. При этом анализ художественного мира рекламного ролика позволяет утверждать, что мотив «восстания» задуман, но не реализован: последний эпизод не стал «ударным местом» - тем «роinte», о котором Л.С. Выготский говорил как об условии эстетической реакции, месте, где «происходит как бы короткое замыкание двух противоположных токов» [5, с. 174], обусловливающее катарсис и, следовательно, психологически созидающий эффект.

«Восстановление» в анализируемом медианарративе немотивированно, «кульминационный момент» мрачен: герой предстает в бедной неуютной захламленной комнате на столе между темными и пустыми фаянсовыми вазами. Эмоционально тема «воскрешения» не поддержана ни музыкой, ни визуальными образами. Более того, депрессивность кульминационного «возвращения в жизнь» усиливается контрастностью с эмоциональной яркостью предыдущего, восьмого эпизода, в котором смерть представлена как ликование - образом салюта, в который превращается запущенная «свеча бедствия».

Таким образом, анализ показал, что в художественном мире рекламного текста мотив смерти, использованный для привлечения внимания, не трансформируется в мотив «воскрешения». Более того, эмоционально поддержан посыл о том, что «воскрешение» бессмысленно и представляет собой возврат в одинокий неуютный мир.

Обыденность образа героя суицидального рекламного нарратива - «енота» и реалистичность окружающей его обстановки актуализируют процессы идентификации зрителя с героем и, следовательно, могут способствовать провокации мотива саморазрушения. Для верификации сформулированного на основе проведенного анализа предположения было проведено эмпирическое исследование, в ходе которого определялась семантика «енота»- героя ролика, и сопоставлялась с семантикой внеконтекстного животного «енот», а также с семантикой животных, наделенных символическим значением: «волк», «медведь», «кошка» и «собака».

\section{Результаты}

\section{Определение особенностей восприятия рекламного нарратива}

В исследовании приняли участие 103 человека: 77 учащихся десятых классов двух общеобразовательных школ г. Иркутска и 26 студентов факультета сервиса и рекламы ИГУ, всего 55 юношей и 48 девушек.

Задачей, решаемой в ходе исследования, было выявление особенностей восприятия героя рекламного текста. С помощью метода семантического дифференциала определялась семантика героя рекламного ролика, 


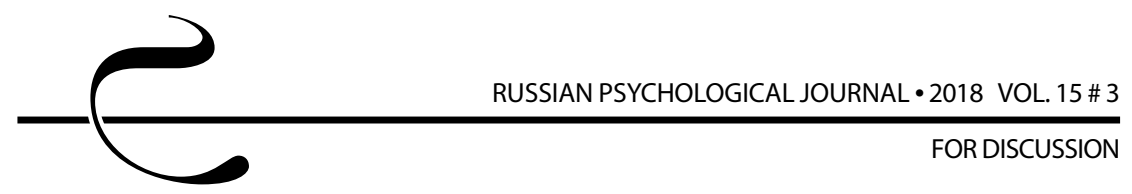

и проводилось ее сравнение с семантикой «человека» и обладающих стереотипным значением животных: «кошки», «собаки», «волка» и «медведя», а также с семантикой животного «енот».

Исследование проводилось в два этапа: на первом испытуемые оценивали вербальные стимулы, на втором определяли семантику героя нарратива «енота» после просмотра рекламного ролика.

Исходя из цели исследования, 25-шкальный вариант классического семантического дифференциала был дополнен шкалами: «смысл - бессмысленность», «жизнь - смерть», «общение - одиночество», «праздник будни», «новое - старое», «временный - вечный», «суета - покой».

Полученные в результате исследования данные подверглись процедуре факторного анализа, который осуществлялся методом главных компонент. Вращение факторов производилось методом варимакс. Для оценки надежности вычисления элементов корреляционной матрицы и возможности ее описания с помощью факторного анализа использовался тест Кайзера Мейера - Олкина (КМО) и коэффициент сферичности Бартлетта. После выделения факторной структуры с использованием уравнений множественной регрессии вычислялись факторные оценки выявленных переменных.

Учитывая оценки величины значения каждого фактора, мы выделили пять факторов, объясняющих после варимакс вращения $68,618 \%$ суммарной дисперсии переменных.

В первый фактор с высокими факторными нагрузками вошли шкалы: «новый - старый» $(0,762)$, «праздник - будни» $(0,700)$, «полнота - пустота» $(0,699)$, «общение - одиночество» $(0,664)$, «интересный - неинтересный» $(0,652)$, «смысл - бессмысленность» $(0,647)$, «жизнь - смерть» $(0,625)$, «наполненность - пустота» $(0,558)$. Он обозначен «фактором общительности».

Второй фактор «легкости» оказался представленным шкалами: «легкий тяжелый» $(0,802)$, «простой - сложный» $(0,728)$, «расслабленный - напряженный» $(0,692)$, «порядок - хаос» $(0,649)$. Третий - «фактор силы» - составили шкалы «крупный - мелкий» $(0,767)$, «сильный - слабый» $(0,751)$, «активный пассивный» $(0,647)$ и «быстрый - медленный» $(0,569)$. В четвертый фактор «ума» вошли шкалы «острый - тупой» $(0,758)$ и «умный - глупый» $(0,679)$. Шкалы «временный - вечный» $(0,796)$, «суета - покой» $(0,690)$ и «влажный - сухой» $(0,570)$ составили пятый «фактор времени».

Далее мы выявляли особенности оценки героя рекламного ролика, предполагая, что они проявятся в процессе сопоставления с семантикой наделенных стереотипным значением животных: волка, медведя, кошки и собаки, внеконтекстного образа енота, а также с семантикой «человека».

Анализ показал, что семантика животного енот значительно отличается от семантики «енота» - героя рекламного ролика. С помощью критерия 
Манна - Уитни обнаружено, что по 29-ти шкалам и четырем факторам различия в их оценке достоверно различны ( $p \leq 0,05)$. При этом оценка животного «енот» близка оценкам родового понятия «человек»: только по первому фактору различия достоверны: «человек» более общителен $(p=0,043)$. Таким образом, исходная семантика использованного в ролике животного, наиболее близкая семантике «человека», позволяет интенсифицировать процессы идентификации при восприятии медианарратива. Это является основанием суждения о том, что трансформация семантики «енота», выявленная после просмотра ролика, может оказывать влияние на изменение смысловых установок зрителей относительно собственной жизни.

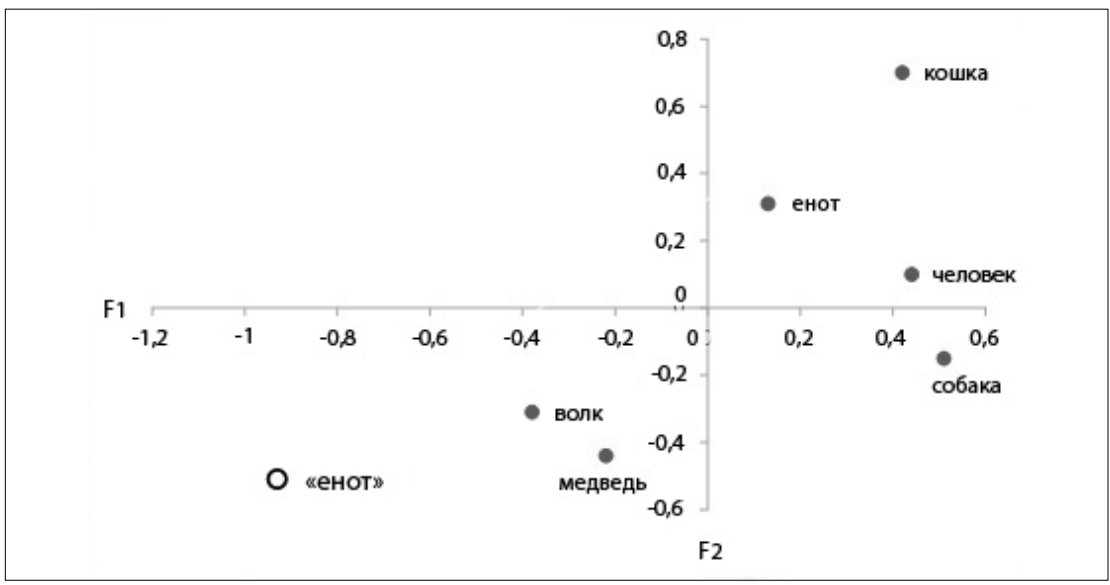

Рисунок 1. Значение стимулов в семантическом пространстве «общительности» (фрактор 1) и «легкости» (фрактор 2)

Figure 1. Stimuli in the 'sociability' (factor 1) and 'lightness' (factor 2) semantic spaces

Выявлено, что рекламный «енот» - самый «одинокий»: его оценка по фактору «общительности»-0,93; он даже более одинокий, чем «волк» (в стереотипное представление о котором входит понятие одиночества). Он же-самый «тяжелый» $(-0,51)$, даже более тяжелый, чем получивший ожидаемо высокую оценку по этому фактору «медведь». На рисунке 1 показано, что рекламный герой располагается в той же части семантического пространства, что «волк» и «медведь», а вербальный стимул «енот» оценен респондентами значительно позитивнее - он наиболее близок оценке стимула «человек», а затем - оценке домашних животных: кошки и собаки. На основании этих данных можно судить об антропоморфизации внеконтекстного стимула «енот» при его восприятии, 
а также о том, что трансформация семантики рекламного «енота» в зону негативных оценок связана с наделением его транслируемыми рекламным нарративом деструктивными смыслами.

В зоне высоких значений по фактору силы ожидаемо оказались стимулы: «волк» $(0,56)$, «собака» $(0,5)$ и «медведь» $(0,45)$. Герой рекламного ролика слаб $(-0,1)$, как слабы «человек» $(-0,15)$, «енот» $(-0,12)$ и «кошка» $(-0,22)$. В художественном мире ролика «енот» абсолютно пассивен и покорен обстоятельствам, поэтому низкие значения его оценок по фактору «силы» закономерны. Менее ожидаема выявленная семантика «слабости» у «человека», маркирующая делегирование ему значения «беспомощности». Рекламный герой, как и внеконтекстный образ енота, воспринимается «глупым» (F4 = -0,24), а самой «умной» оказывается кошка $(0,2)$, что вполне соответствует стереотипному значению этого образа.

Согласно значениям фактора «временности», герой рекламного нарратива наделен семантикой покоя и вечности (F5 =-0,12). На рисунке 2 представлено место рекламного персонажа в семантическом пространстве шкал «временный - вечный» и «суета - покой»: образ рекламного «енота»в зоне отрицательных значений. Можно заключить, что оценка по этим шкалам отражает восприятие персонажа как близкого смерти, образ которой наделен в культуре значением вечного покоя.

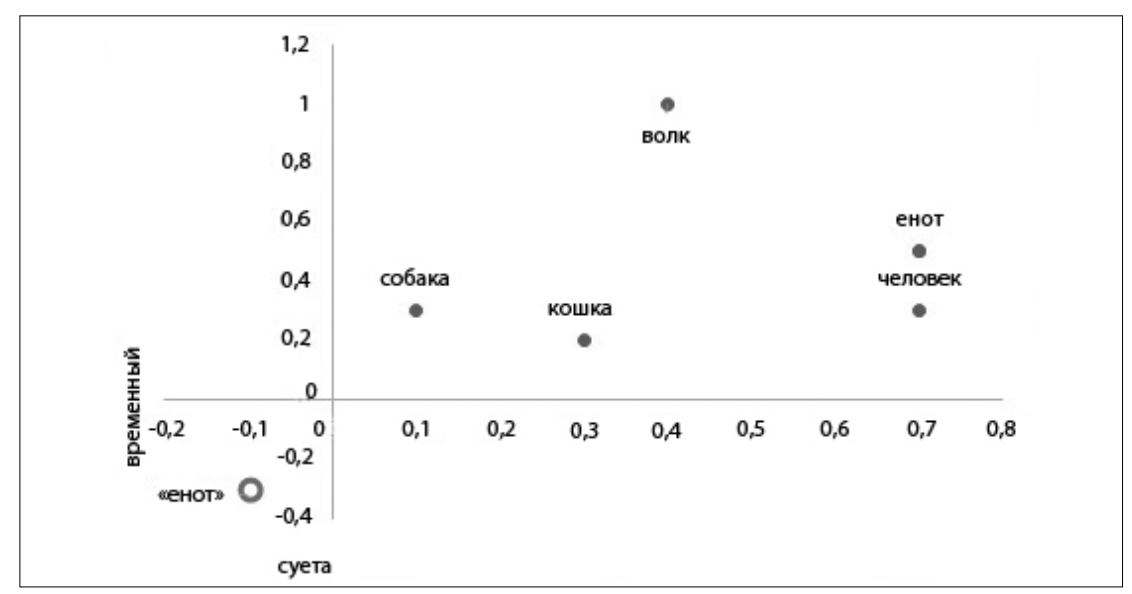

Рисунок 2. Значения стимулов в семантическом пространстве шкал «временный - вечный» и «суета - покой»

Figure 2. Stimuli in the 'temporary-eternal' and 'bustle-peace' semantic spaces 
Исходя из предположений о трансляции роликом деструктивных смыслов, мы использовали для оценки персонажей шкалы «жизнь - смерть» и «смысл бессмыслица». Исследование показало, что герой анализируемого ролика помещен в зону смерти $(-1,9)$ и бессмысленности $(-0,6)$ (рисунок 3). В этом особенность его восприятия, по сравнению с другими оцениваемыми стимулами, причем различия в оценке статистически значимы $(p=0,00)$. Домашние животные оцениваются по этим экзистенциально значимым шкалам более высоко, чем традиционные для национальной культуры персонажи: медведь и волк. Исходная семантика «енота» (0,42 по шкале «смысл - бессмысленность» и 1,35 по шкале «жизнь - смерть») значительно трансформировалась после просмотра ролика, при этом выявленные изменения негативны.

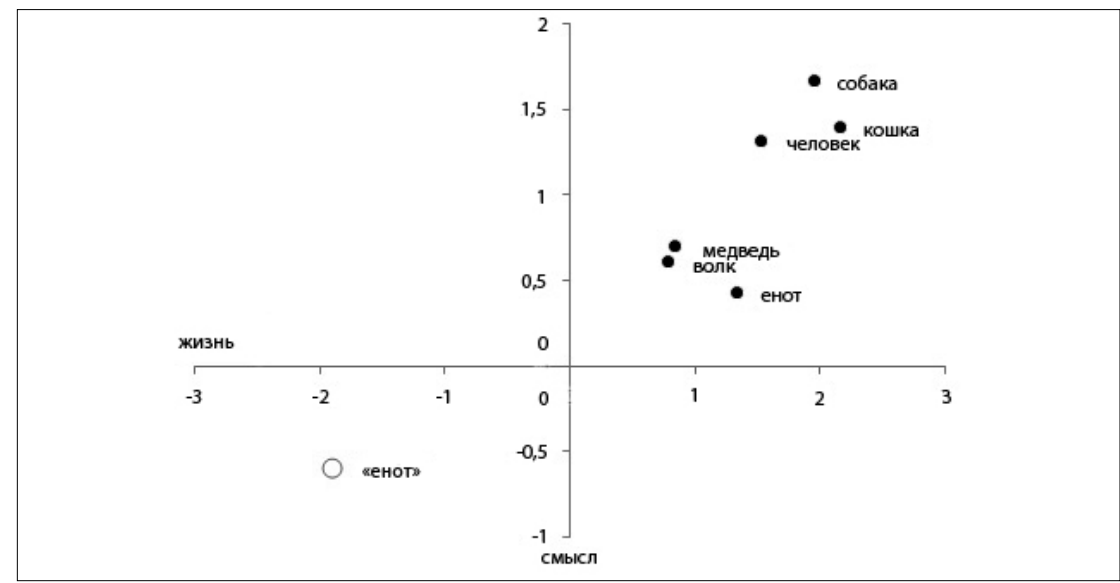

Рисунок 3. Значения стимулов в семантическом пространстве шка^ «жизньсмерты» и «смысл - бессмысленносты»

Figure 3. Stimuli in the 'life-death' and 'meaning-meaninglessness' semantic spaces

Обнаруженный деструктивный сдвиг семантики «енота», спровоцированный восприятием медийного нарратива, демонстрирует и анализ значений оцениваемых стимулов по шкалам «праздник - будни» и «общение - одиночество». До просмотра ролика испытуемые поместили стимул «енот» в семантическую зону «праздничности» $(0,5)$ и «общения» $(0,4)$. Оценка «енота» - героя рекламного нарратива - в зоне выраженных отрицательных значений, причем различия с оценками других стимулов, определяемые с помощью коэффициента Манна - Уитни, статистически достоверны (рисунок 4). 

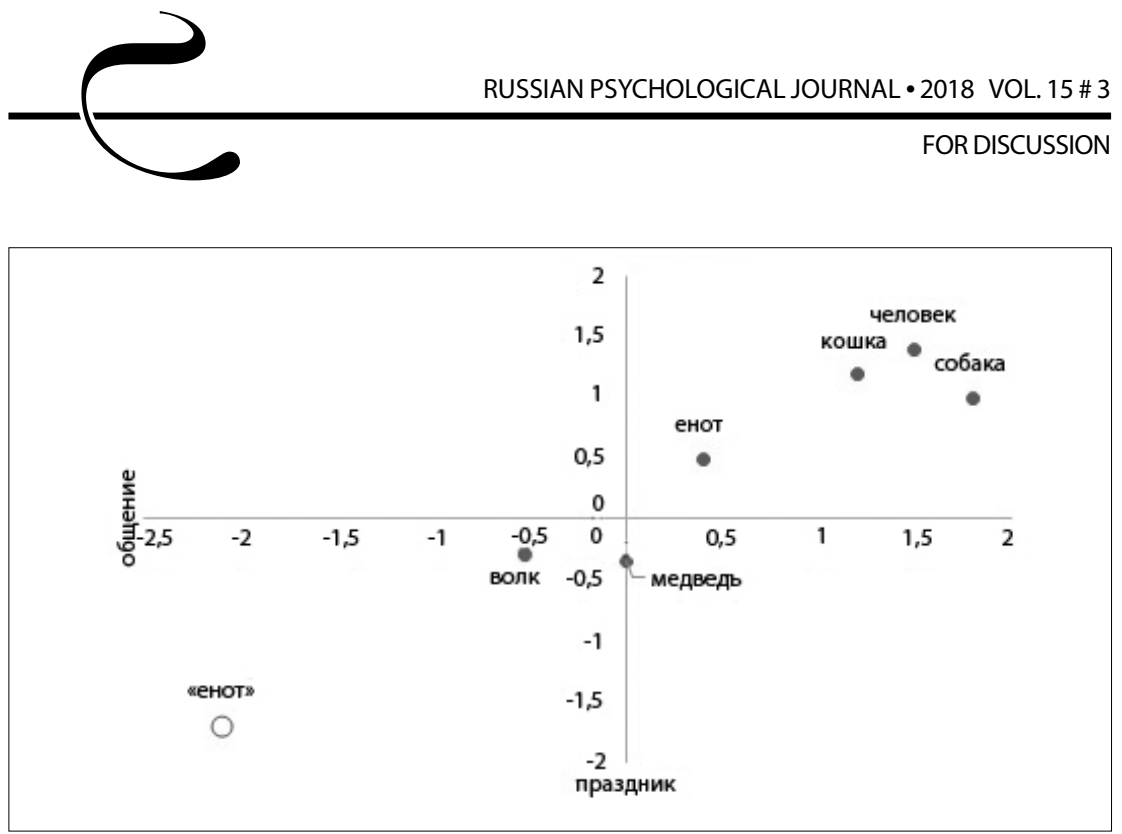

Рисунок 4. Значения стимулов в семантическом пространстве шкал «празАник - будни» и «общение - одиночество»

Figure 4. Stimuli in the 'holiday-weekday' and 'communication-loneliness' semantic spaces

\section{Обсуждение результатов}

В результате проведенного исследования, во-первых, определены смыслы, транслируемые рекламным роликом и выявленные в процессе его имманентного психологического анализа. Показано, что смысловая структура анализируемого нарратива двойственна: на прагматическом уровне, целью которого является актуализация потребительской мотивации, рекламное сообщение пытается передать информацию, связанную с мотивом оживления, восстановления, выздоровления. Анализ художественной организации текста позволил предположить, что другой реализованный в ролике уровень экзистенциальный, связанный с мотивом смерти, невыносимости жизни и безальтернативности ухода из нее, является доминантным, определяет семантику рекламного нарратива и транслируемые им смыслы.

Достоверность сформулированного на основе психологического анализа рекламного нарратива суждения о его деструктивном содержании была проверена в процессе эмпирического исследования. Выявленные различия в оценке животного - «енота» и героя рекламного ролика - показали, что семантика животного претерпела выраженную деструктивную трансформацию. Отсутствие у «енота» устойчивой символической семантики (как у животных, используемых для сравнения: волка, медведя, кошки и собаки) обусловило 
активизацию процессов его антропоморфизации и идентификации зрителя с образом героя. Это позволяет считать, что рекламный «енот» может провоцировать негативную мотивацию, в частности, суицидальную.

Вопрос о мотивирующем потенциале медийных текстов является трудным, нерешенным и требующим внимания в силу возрастающего значения медийных сообщений $[28,29,30,31]$. Суждение о психологической деструкции или созидательности медианарративов должно опираться на комплексный психологический анализ, учитывающий не только содержательный уровень медиатекста, но и уровень организации его формы. В процессе анализа образных, архитектонических и музыкальных особенностей текста показано, что семантика образа животного, исходно не наделенного символическим значением, трансформируется в рекламном нарративе, причем характер изменений определяется художественным контекстом и влияет на транслируемые потребителю смыслы.

\section{Литература}

1. Ефименко В. А. Кинонарратив как объект нарратологического анализа // Филологические науки. Вопросы теории и практики. 2013. № 9-2 (27). C. 87-90.

2. Chatman S. Coming to Terms: The Rhetoric of Narrative in Fiction and Film. Ithaca: Cornell University Press, 1990. 256 p.

3. Fludernik M. Histories of Narrative Theory (II): From Structuralism to the Present // A Companion to Narrative Theory / J. Phelan, P. J. Rabinowitz (Eds.). Malden: Blackwell Publishing, 2005. P. 36-59.DOI: 10.1002/9780470996935.ch3

4. Narratology in the Age of Cross-Disciplinary Narrative Research / S. Heinen, R. Sommer (Eds.). Berlin - N. Y.: Walter de Gruyter, 2009. 309 p.

5. Выготский Л. С. Психология искусства. М.: Лабиринт, 1997. 416 с.

6. Барт Р. Мифологии. М.: Изд-во им. Сабашниковых, 2000. 320 с.

7. Мети К. Воображаемое означающее. Психоанализ и кино. СПб: Изд-во Европейского ун-та, 2010. 336 с.

8. Кафтанджиев Х. Семиотика Абсолюта. М.: РИП-Холдинг, 2006. 354 с.

9. ван Дейк Т. А. Дискурс и власть: Репрезентация доминирования в языке и коммуникации / пер. с англ. М.: Книжный дом «ЛИБРОКОМ», 2013. $344 \mathrm{c}$.

10. Матисон Д. Медиа-дискурс: Анализ медиа-текстов. Харьков: Гуманитарный центр, 2013. 264 с.

11. Винтерхоффр-Шпурк П. Медиапсихология: Основные принципы. Харьков: Гуманитарный центр, 2016. 268 с.

12. Пронина Е. Е. Психологическая экспертиза рекламы: Теория и методика психотехнического анализа рекламы. М.: РИП-холдинг, 2000. 100 с. 
13. Смирнова Е. О., Соколова М. В. Психолого-педагогическая экспертиза мультфильмов для детей и подростков // Культурно-историческая психология. 2014. Т. 10, № 4. С. 4-11.

14. Reeves B., Yeykelis L., CummingsJ.J.The Use of Media in Media Psychology //Media Psychology.2016.Vol. 19, Issue 1.P.49-71.DOl:10.1080/15213269.2015.1030083

15. Маклюэн Г. М. Понимание медиа: Внешние расширения человека. М.: Кучково поле, 2017. 464 c.

16. Кыштымова И.М. Психосемиотика креативности. Иркутск: Изд-во ИГУ, 2008. $579 \mathrm{c}$.

17. Ломов Б. Ф. Системность в психологии. М.: Изд-во «Институт практ. психологии», Воронеж: НПО «МОДЭК», 1996. 384 с.

18. Кыштымова И. М. Психологическая безопасность в информационном пространстве: имманентный анализ текста и его семантика // Психология в экономике и управлении. 2017. Т. 9, № 1. С. 17-23.

19. Гаспаров М. Л. Избранные труды. Т. ІІ. О стихах. М.: Языки русской культуры, 1997. 504 с.

20. «Клей секунда» / Енот - Рекламный ролик (Ночь пожирателей рекламы) // Одноклассники. URL: https://ok.ru/video/8396145982 (дата обращения 10.07.2018).

21. Кубрак Т. А. Информационно-психологическая безопасность в кинодискурсе: состояние проблемы // Психология дискурса: проблемы детерминации, воздействия, безопасности / под ред. А. Л. Журавлева, Н. Д. Павловой, И. А. Зачесовой. М.: Изд-во ИП РАН, 2016. С. 220-241.

22. Попов Ю. В., Пичиков А. А. Суицидальное поведение у подростков. СПб.: СпецЛит, 2017. 366 с.

23. Савчук В. В. Медиафилософия. Приступ реальности. 2-е изд., испр. и доп. СПб.: Изд-во РХГА, 2014. 350 с.

24. Okdie B. M., Ewoldsen D. R., Muscanell N. L., et al. Missed Programs (You Can't TiVo This One). Why Psychologists Should Study Media // Perspectives on Psychological Science. 2014. Vol. 9, Issue 2. P. 180-195. DOI: 10.1177/1745691614521243

25. Folkvord F., Reit J. $V$. The persuasive effect of advergames promoting unhealthy foods among children: A meta-analysis // Appetite. 2018. Vol. 129. P. 245-251. DOI: 10.1016/j.appet.2018.07.020

26. Dubreu-Béclin A. Exposition aux écrans et croissance psychique. Exposure to screens and psychic development in children // L'Évolution Psychiatrique. 2018. Vol. 83, Issue 3. P. 399-414. DOI: 10.1016/j.evopsy.2018.05.002

27. Вихристюк О. В. Влияние средств массовой информации на суицидальное поведение подростков и молодежи (обзор зарубежных источников) // Современная зарубежная психология. 2013. Т. 2, № 1. С. 100-108. 
28. Степнова Л. А. Психологическая экспертиза информации, пропагандирующей подростковый суицид // Развитие профессионализма. 2016. № 1 (1). С. 222-223.

29. Baker D., Fortune S. Understanding SelfHarm and Suicide Websites: A Qualitative Interview Study of Young Adult Website Users // Crisis: The Journal of Crisis Intervention and Suicide Prevention. 2008. Vol. 29, Issue 3. P. 118-122. DOI: $10.1027 / 0227-5910.29 .3 .118$

30. Ruder T.D. et al. Suicide Announcement on Facebook // Crisis: The Journal of Crisis Intervention and Suicide Prevention. 2011. Vol. 32, Issue 5. P. 280-282. DOI: 10.1027/0227-5910/a000086

31. Longbottom S., Slaughter V. Sources of children's knowledge about death and dying // Philosophical Transactions of the Royal Society B. 2018. Vol. 373, Issue 1754. DOI: $10.1098 /$ rstb.2017.0267

\section{References}

1. Efimenko V. A. Film narrative as object of narratological analysis. Filologicheskie nauki. Voprosy teorii i praktiki - Philological Sciences. Issues of Theory and Practice, 2013, no. 9-2 (27), pp. 87-90 (in Russian).

2. Chatman S. Coming to terms: The rhetoric of narrative in fiction and film. Ithaca, Cornell University Press, 1990. 256 p.

3. Fludernik M. Histories of narrative theory (II): From structuralism to the present. In: J. Phelan, P. J. Rabinowitz (eds.) A companion to narrative theory. Malden: Blackwell Publishing, 2005. P. 36-59. DOI: 10.1002/9780470996935.ch3

4. Heinen S., Sommer R. (eds.) Narratology in the age of cross-disciplinary narrative research. Berlin-N. Y., Walter de Gruyter, 2009. 309 p.

5. Vygotskii L. S. Psikhologiya iskusstva [Psychology of art]. Moscow, Labirint Publ., 1997. 416 p.

6. Barthes R. Mythologies. New York, Hill \&Wang, 1957 (Russ. ed.: Bart R. Mifologii. Moscow, Izd-vo im. Sabashnikovykh Publ., 2000. 320 p.).

7. Metz Ch. Psychoanalysis and cinema: The imaginary signifier. London, MacMillan, 1982 (Russ. ed.: Metts K. Voobrazhaemoe oznachayushchee. Psikhoanaliz i kino. St. Petersburg, European University Publ., 2010. 336 p.).

8. Kaftandzhiev Kh. Semiotika absolyuta [Semiotics of absolute]. Moscow, RIP-Kholding Publ., 2006. 354 p.

9. van Dijk T. A. Discourse and power: Representation of dominance in language and communication (Russ. ed.: van Deik T. A. Diskurs i vlast': Reprezentatsiya dominirovaniya vyazyke i kommunikatsii. Moscow, Librokom Publ., 2013.344 p.).

10. Matheson D. Media discourses: Analysing media texts (Russ. ed.: Matison D. Media-diskurs: Analiz media-tekstov. Kharkov, Gumanitarnyi tsentr Publ., 2013. 264 p.). 


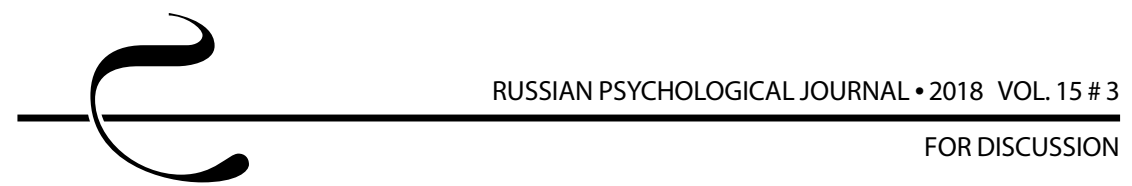

11. Winterhoff-Spurk P. Metapsychology:Basic principles (Russ. ed.:VinterkhoffShpurk P. Mediapsikhologiya: Osnovnye printsipy. Kharkov, Gumanitarnyi tsentr Publ., 2016. 268 p.).

12. Pronina E. E. Psikhologicheskaya ekspertiza reklamy: Teoriya i metodika psikhotekhnicheskogo analiza reklamy [Psychological expertise of an advertisement: Theory and methodology of psycho-analysis of an advertisement]. Moscow, RIP-kholding Publ., 2000. $100 \mathrm{p}$.

13. Smirnova E. O., Sokolova M. V. Psychological and pedagogical expertise of animated films for children and teenagers. Kul'turno-istoricheskaya psikhologiya - Cultural-Historical Psychology, 2014, V. 10, no. 4, pp. 4-11 (in Russian).

14. Reeves B., Yeykelis L., Cummings J. J. The use of media in media psychology. Media Psychology, 2016, V. 19, Issue 1, pp. 49-71. DOI: 10.1080/ 15213269.2015.1030083

15. McLuhan M. Understanding media: The extensions of man. Berkeley, Gingko Press, 1964 (Russ. ed:: Maklyuen G. M. Ponimanie media:Vneshnie rasshireniya cheloveka. Moscow, Kuchkovo pole Publ., 2017. 464 p.).

16. Kyshtymova I. M. Psikhosemiotika kreativnosti [Psychosemiotics of creativity]. Irkutsk, ISU Publ., 2008. 579 p.

17. Lomov B. F. Sistemnost'v psikhologii [Consistency in psychology]. Moscow, Voronezh, Modek Publ., 1996. 384 p.

18. Kyshtymova I. M. Psychological security in the information space: An immanent analysis of the text and its semantics. Psikhologiya vekonomike i upravlenii - Psychology in Economics and Management, 2017, V. 9, no. 1, pp. 17-23 (in Russian).

19. Gasparov M. L. Izbrannye trudy. T. II. O stikhakh [Selected works. V. 2. On the poems]. Moscow, Yazyki russkoi kul'tury Publ., 1997. 504 p.

20. "Sekunda" glue: The raccoon promotional video: The night of the ad eaters. (Odnoklassniki). Available at: https://ok.ru/video/8396145982 (Accessed 10 July 2018).

21. Kubrak T. A. Information and psychological security in the cinema discourse: Current status of the problem. In: A. L. Zhuravlev, N. D. Pavlova, I. A.Zachesova (eds.) Psikhologiya diskursa:problemy determinatsii, vozdeistviya, bezopasnosti [Discourse psychology: Problems of determination, influence, and security]. Moscow, Institute of Psychology RAS, 2016, pp. 220-241.

22. Popov Yu. V., Pichikov A. A. Suitsidal'noe povedenie u podrostkov [Suicidal behaviour in adolescents]. St. Petersburg, Spetslit Publ., 2017. 366 p.

23. Savchuk V. V. Mediafilosofiya. Pristup real'nosti [Media philosophy: Reality attack]. St. Petersburg, Russian Christian Academy for Humanities Publ., 2014. $350 \mathrm{p}$. 
для дискУсСии

24. Okdie B. M., Ewoldsen D. R., Muscanell N. L., et al. Missed programs (You can't TiVo this one). Why psychologists should study media. Perspectives on Psychological Science, 2014, V. 9, Issue 2, pp. 180-195. DOI: $10.1177 /$ 1745691614521243

25. Folkvord F., Reit J. V. The persuasive effect of advergames promoting unhealthy foods among children: A meta-analysis. Appetite, 2018, V. 129, pp. 245-251. DOI: 10.1016/j.appet.2018.07.020

26. Dubreu-Béclin A. Exposition aux écrans et croissance psychique. Exposure to screens and psychic development in children. L'Évolution Psychiatrique, 2018, V. 83, Issue 3, pp. 399-414. DOI: 10.1016/j.evopsy.2018.05.002

27. Vikhristyuk O. V. Impact of Mass-media information on suicidal behaviour of adolescents and youths (review of foreign sources). Sovremennaya zarubezhnaya psikhologiya - Journal of Modern Foreign Psychology, 2013, V. 2, no. 1, pp. 100-108 (in Russian).

28. Stepnova L. A. Psychological expertise of information that promotes adolescent suicide. Razvitie professionalizma-Development of Professionalism, 2016, no. 1 (1), pp. 222-223 (in Russian).

29. Baker D., Fortune S. Understanding selfharm and suicide websites: A qualitative interview study of young adult website users. Crisis: The Journal of Crisis Intervention and Suicide Prevention, 2008, V. 29, Issue 3, pp. 118-122. DOI: $10.1027 / 0227-5910.29 .3 .118$

30. Ruder T. D. et al. Suicide announcement on Facebook. Crisis: The Journal of Crisis Intervention and Suicide Prevention, 2011, V. 32, Issue 5, pp. 280-282. DOI: 10.1027/0227-5910/a000086

31. Longbottom S., Slaughter V. Sources of children's knowledge about death and dying. Philosophical Transactions of the Royal Society, 2018, V. 373, Issue 1754. DOI: $10.1098 /$ rstb.2017.0267 